\title{
The Teaching Reform of Electronic Technology Course Based on the Concept of CKDI Engineering Education
}

\author{
Yanfei Liü, a, Daoping Wang ${ }^{1, b}$, Qiuyan Wang ${ }^{1, b}$ and Hao Zhen ${ }^{1, b}$ \\ ${ }^{1}$ Xi'an Research Institute of High Technology, Xi'an 710025, China \\ abbmcu@126.com, bwonderping@163.com
}

Keywords: electronic technology; teaching reform; innovation consciousness; practical ability; CKDI

\begin{abstract}
The objective of our present study, the teaching reform of electronic technology course, is to cultivate students' innovation consciousness, promote their practical ability and encourage their team-work spirit. The CKDI engineering education concept we introduced, reconstructed the curriculum system on the basis of the structure of electronic system. We also adopted the task-driven teaching mode and reformed the course assessment method, which highlights the process of evaluation. Our teaching experience indicates that the adoption of the CKDI concept in the process of the electronic technology course teaching can achieve a better result in both teaching effects and the students' all-round development.
\end{abstract}

\section{Introduction}

The electronic technology course includes analog electronic technology and digital electronic technology. These courses show the theoretical questions in an engineering way, and play an important role in cultivating students' innovative consciousness and practical ability. The teaching contents of the course include the basic theory and the analysis method of basic circuits, which is relatively stable, while the new technology and new devices update quickly. So how to improve students' ability of engineering practice by organizing the electronic technology course teaching effectively, is becoming an important content of teaching reform[1].

Since introduced in China on the 2005, CDIO engineering education mode has made a far-reaching influence on China engineering education. CDIO consists of Conceive, Design, Implement and Operate. The life cycle of a product from its development to operation was used to teach the students how to complete a project actively and practically during the mode.

As the electronic technology course is inextricably bound up with the practical engineering, teaching the electronic technology course according to CDIO mode can effectively cultivate students' innovation consciousness and practice ability[2].This paper proposes an improved CDIO mode named CKDI, which means Conceive, Knowledge, Design and Implement[3].

\section{The Reform of Electronic Technology Course System Based on CKDI}

According to the CKDI concept, the global framework for electronic systems should be taught to students, which makes it convenient for students to understand concepts and to design practical electronic systems. Therefore, the content structure of electronic technology course should be replanned according to the basic structure of electronic systems, the teaching contents should be updated timely, not only to keep pace with the rapid development of electronic technology, but to improve the students' innovation consciousness and practice ability constantly.

\subsection{Organizing the teaching content according to the basic structure of electronic systems}

Modern electronic systems are usually analog-digital mixed system, the analog parts of the system amplify and filter the input signal, driving the output signal and managing the power, While the digital parts of the system complete complex control functions (in most cases need a MCU/DSP/ARM/FPGA and other programmable devices). The convert between analog and digital parts is done through DAC(digital to analog converter) and ADC(analog to digital converter). Organizing the teaching content of electronic technology according to such a structure, the electronic technology course contents will have a more clear direction[4]. 
The electronic solutions on the system board was provided by Cui Meng, a staff member of TI company, the teaching content can be expressed as Fig. 1.

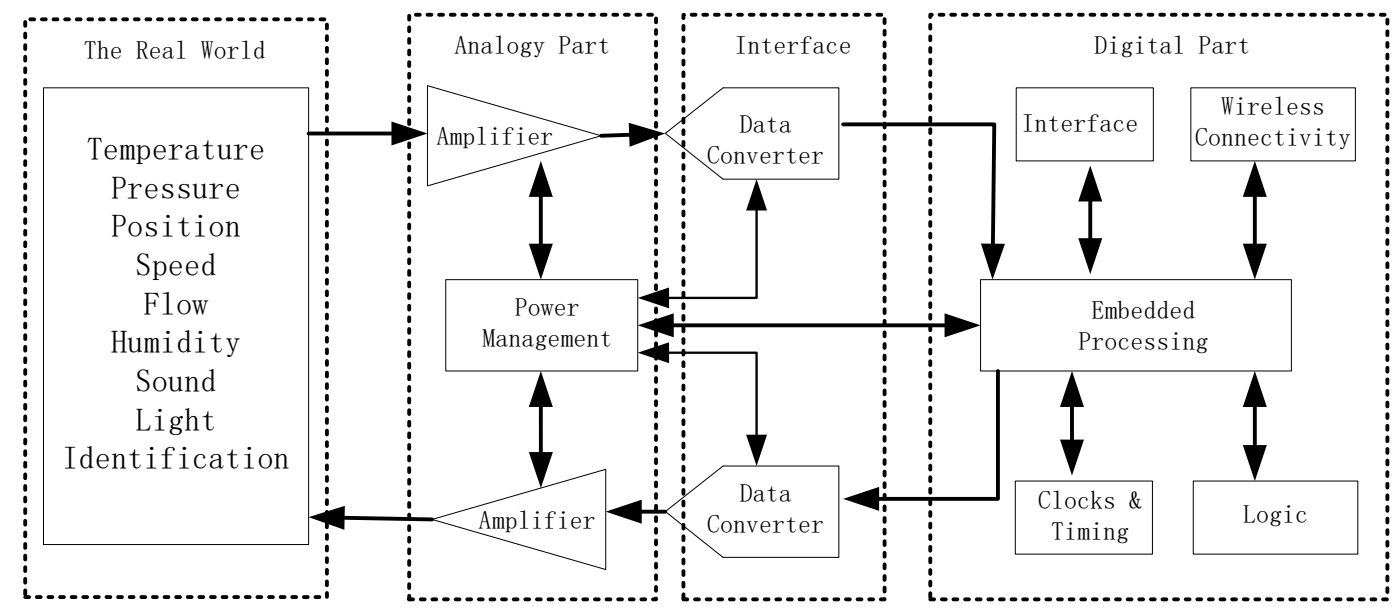

Fig. 1 the Teaching Content Structure of Electrical Technology Course

\subsection{Update the teaching content timely}

With the continuous development of electronic technology, new technology and new devices emerge in endlessly. And the teaching content of the electronic technology course has to be updated constantly. On this account, we add something new to the teaching content, such as switching power supply, switch capacitor, class D power amplifier, phase lock loop, FPGA etc., We hope it helpful to make the students keep up with the academic frontiers of electronic technology[5].

According to the CKDI engineering education concept, the teacher was recommended to let the students understanding and practice through all teaching process constantly. Therefore, the teacher should alter the traditional teacher-centered teaching process into the student-centered teaching process.

\subsection{Task-driven teaching mode}

The task-driven approaches was used during authors' teaching process, as the teaching contents of electronic technology course are closely corresponding to certain practical electronic system module, We take designation of an electronic system as a starting point to guide the student to participate in discussing and thinking, and to cultivate the students' "C" (Conceive Ability) and "D" (Design Ability) [6].

For example, to explain how to use the comparator, the author used the temperature control system in electronic water heater as an example, which inspired students to think about how to realize the temperature control in a certain range and deducing the structure of the hysteresis comparator step by step.

\subsection{Make the Classroom as a "Lab" by Simulating and Demonstrating Circuit Module}

In the process of teaching, the circuit working principle was simulated by Multisim, software for circuit simulation. This is helpful for the student to understand the working process of the circuit intuitively. In the process, the author does not just take the simulation as a simple demo, but makes full use of the feature that the model parameters can be modified in Multisim, real-timely modifying the parameters such as working temperature, disorder and drift parameters in use, just to let the students understand the specific issues in the circuit designation and realization. For example, when teaching how to improve the stability of operation point, the author vividly shows the process that operating point changes in the drift of temperature in PN junction by changing the operating temperature parameter of the device[7].

The simulation circuit and results are as follows. 


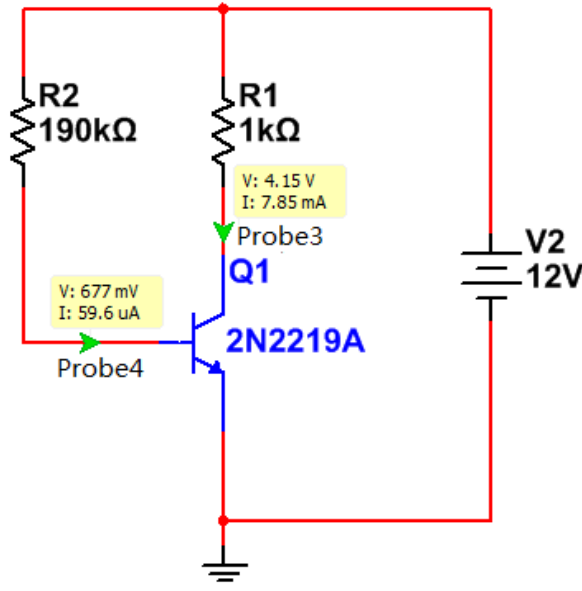

temperature1 T_ABS $=27$

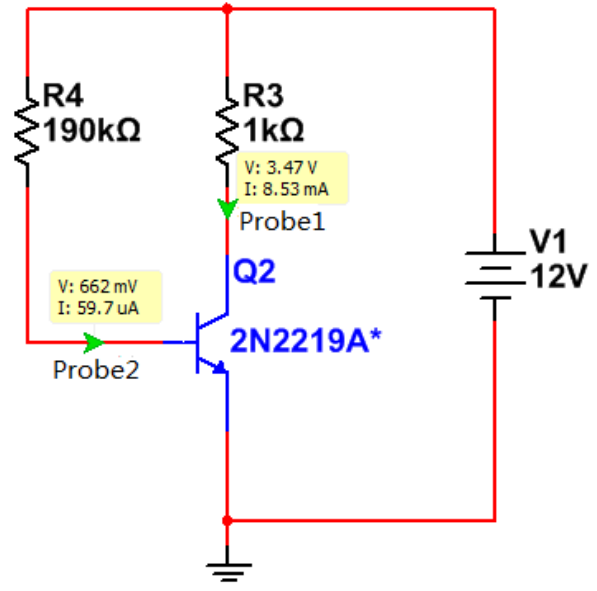

temperature2 T_ABS=50

Fig. 2 the Simulation Circuit of Stabilize Operation Point

At the same time, the author's teaching team produces typical circuit demonstration modules and realizes the unity of the circuit demonstration and the waveform observation in the classroom to make the classroom into a "lab". Through the above measures, the author can train students' "K" (acquire Knowledge ability) and "I" (Implement ability).

\subsection{Set up the Interest Group and Realize the Whole Process of CKDI Training}

With the electronic technology basic course teaching process according to the CDIO model, quite a number of students show a keen interest in the electronic system design. The author sets up interest group for these students, teaches them by project-driven teaching, so that the students can experience the whole $\mathrm{C}, \mathrm{K}, \mathrm{D}$ and I process[8].

For these students, the teachers assign the corresponding comprehensive design of the subject in accordance with the teaching schedule. And the students must complete the analysis, design, installation, debugging, etc. At the same time, the teacher encourages and supports these students to put forward innovative ideas and helps them to complete the design and manufacture of the circuit. Through this process, training students' Team working spirit and innovation ability[9].

\section{The Reform of Electronic Technology Curriculum Evaluation Mode Based on CKDI}

According to the traditional course exam way, the result is determined by answering the test paper in the end of term. By this kind of exam, the teacher just assesses the students' ability to answer papers, and do not assesses the students' engineering practice ability. CKDI engineering education models pay attention to cultivate students' ability to solve practical problems; therefore, the traditional course exam way is inappropriate. The author's own teaching team tries a course examination way of combining process evaluation and result evaluation. By this way the test result includes usually result and terminal examinations result, which incorporates the combination of understanding knowledge and using knowledge.

\section{Conclusion}

The author's teaching practice shows that using the CKDI concept to guide the electronic technology course teaching can effectively improve the teaching effect, raise student's innovative consciousness and ability of engineering practice, promote the students' all-round development. The students guided through CKDI have achieved excellent results in National Undergraduate Electronic Design Contest and other Science and Technology Innovation Competition.

\section{References}

[1]. GuPeihua, ShenMinfeng, LuXiaoHua. To meet engineering education. Beijing: higher education press, 2009, 4. 
[2]. GuPeihua, BaoNengsheng, Kang Quanli, etc., CDIO in China (up), higher engineering education research, 2012 (3), P24-39.

[3]. QianJing, Chen Anjun, Teaching trial and thinking in packaging engineering specialty with CDIO concept, journal of southwest normal university (natural science edition), 2012, 33 (1), P137-140.

[4]. Wang wei, Wang Dianjun, Shen Aiming, etc., teaching system reform and exploration in mechatronic engineering professional based on CDIO personnel training model, journal of Anhui normal university (natural science edition), 2010, 55 (2), P136-138.

[5]. Zhou Yan, Huai Wenjun, Application and practice in electronic design competition with CDIO teaching pattern, Suzhou vocational college journal, 2010 , (2), P7 1-73.

[6]. GuPeihua, Li Yiping, Shen Minfeng, etc., design oriented E IP_CDIO innovative engineering talent training m ode, China's higher education, 2009 (3), P47-49.

[7]. Liu Bao, Peng Fang, etc., science and technology competition and college students' innovative ability Gaining practice with CDIO model, China education technology and equipment, 2012(6), P53-54.

[8]. WuQingxiu, OuJun, ZhouXiayu, the race-driven standard ability teaching curriculum development, Acta innovation of science and technology, 2011 (22), P 155-156.

[9]. Chen Ke-li, Huang Xiang-nian, Pen Hong, "Research of Embedded Teaching Reform Based on CDIO”, 2010 2nd International Conference on Education Technology and Computer (ICETC), 2010, pp:V4-30-V4-33. 